\title{
The Effects of Training Methods and Eye-Hand Coordination on Groundstroke Accuracy
}

\author{
Rekyan Woro Mulaksito Mulyadi \\ Master Program in Sport Sciences \\ Universitas Negeri Yogyakarta \\ Yogyakarta, Indonesia \\ wrekyan@gmail.com
}

\author{
Suharjana \\ Faculty of Sport Sciences \\ Universitas Negeri Yogyakarta \\ Yogyakarta, Yogyakarta \\ suharjana_fikuny@yahoo.com
}

\begin{abstract}
- the aims of the research are to examine (1) differences in the influence of stationary and changing target training method to groundstroke accuracy; (2) differences in the effect of high and low coordination on groundstroke accuracy; and (3) the interaction between training methods and coordination in groundstroke accuracy. The research design is using $2 \times 2$ factorial method. The results show that (1) there is a significant difference between the effect of fixed target and changing target training method on groundstroke accuracy, $p=$ $0.007<0.05$. Changing target training method is better than fixed target training method, with a 1.6 difference; (2) there is a significant difference between the effect of high and low coordination on groundstroke accuracy, $p$ value $=0.001<0.05$. Athletes with high coordination performed better than those with low coordination, with a difference of 2.2 ; (3) there is a interaction between training method and coordination on groundstroke accuracy, $p$ value $=0.000<0.05$.
\end{abstract}

Keywords-groundstroke, fixed target, changing target, coordination

\section{INTRODUCTION}

The groundstroke technique is the first taught to people who are starting to learn Tennis, because this technique is dominantly used during the game. The groundstroke technique is the foundation of modern Tennis. Percentage of techniques used in the game of Tennis is $49 \%$ groundstroke technique and $51 \%$ all other techniques combined. That is, by mastering groundstroke techniques, someone new to learning Tennis could already play the game. Groundstrokes are the most commonly used technique. As discussed by Kriese "the average player performs Groundstrokes in the game $35-45 \%$ of the overall shots during a game or match". Thus, it is essential for players to master the groundstroke technique as it is the most used in the game. Groundstrokes can be done with forehand or often called forehand drive, and can also be done with a backhand or often called a backhand drive, depending on where and where the ball was hit. [1][2]

Based on the intervew with an athlete and coach of Tennis club in FIK UNY, in every tennis game, either junior, senior, or professionel level, the groundstroke is very dominant, both for defensive positions and making an attack to get points. The groundstroke shots requires precision. In the field, it is found that many players, including teenagers, juniors, as well as seniors, failed to utilize groundstroke techniques optimally. In the initial observation, on Tuesday, January 8, 2017 at 3.30 $\mathrm{PM}$, it is observed that the upper groundstroke shots is still random or the ball just entering the opponent's field. The accuracy is still low, and there are still failures in doing groundstroke, for example, the ball get caught on the net and the ball falls outside the field. Other mistakes that often occur at the time preparing for groundstroke, athletes aim too high, not thinking about the direction, and being in a hurry to do it. If this is not resolved, it will be disadvantageous at the time of the match.

The athletes seem hasty in executing the moves, false initial pose, unnatural motion movements, imprecise performances, dull concentrations, improper targets, low accuracy, and less consistent with the results obtained. While doing groundstroke shots, athletes do not concentrate well on the motion of movements and the aim of the groundstroke shots. The portion for groundstroke training is also insufficient compared to other technical training sessions; even the coach does not set targets and giving lacks of instruction during groundstroke training. Based on data during Kejurda Yogyakarta in 2016, it is recorded that in every set of games, loss of points came from the failure of groundstroke shots. The data supports the fact that athletes have not been able to utilize groundstroke shots techniques well at the time of the match. In addition, the accuracy of groundstroke is low. Thus, there is a gap between the instructor's instruction on the target and the result of the execution by athletes in the field. The gap in the implementation of groundstroke shot techniques, especially the low accuracy level, needs to be addressed in the training sessions. Therefore, it is necessary to apply the appropriate training methods to improve the accuracy of groundstroke shots.

Groundstroke training method with fixed targets is a method to train the groundstroke accuracy using the same target continuously without changing the target in a set determined by the coach. "Constant practice: A practice schedule in which the same skill is rehearsed in the same way, without variation, in a series of practice trials" [3]. It means a training where the skill is trained with the same method, without the variation in the series of practice training. In groundstroke training with fixed target, repetition is necessary so there will be automation of movement. The athletes who are trained with this method will easily adapt with trained swings.

Changing target method is a method to train the groundstroke accuracy using changing targets in every set as desired. "Varied practice: A practice schedule in which the same skill is rehearsed in a variety of different ways" [3]. It is a training where the same skill is trained using differrent methods. The advantage of the changing target method is the opportunity to enrich the motion skill techniques that are trained. In this case is the drill of changing target, which 
encourages athletes to present their best ability and posess variation technique development in performing groundstroke with a good placement. Besides, the drill method of changing target demands the athlete to have a better skill [4].

Beside the external factor like the applied training method, internal factor like hand-eye coordination also affects the swing accuracy. "Without good coordination, it will be difficult for the athlete to harmoniously and stimulantly perform the technique with ease" [ 5]. "A well-coordinated athlete will find it easier performing one motion skill and spending less energy than an athlete with low coordination" [6]. Good coordination usually leads to good accuracy, so it is necessary to do serious training regularly and continuously so the athlete's motion skill will increase, which leads to better groundstroke accuracy. Based on the background as described above, the writer is interested in doing the research entitled "The Effects of Training Methods and Eye-Hand Coordination on the Groundstroke Accuracy of Tennis Athlete".

\section{RESUlts}

Hypothesis testing are presented as follows: (a) The difference between the effects groundstroke training method with fixed target and changing target on the athletes' groundstroke accuracy; (b) the difference between the effects of high and low eye-hand coordination on the athletes' groundstroke accuracy; and (c) interaction between groundstroke training method and eye-hand coordination on the athletes' groundstroke accuracy.

TABLE I. DESCRIPTIVE STATISTICS OF GROUNDSTROKE ACCURACY PRETEST AND POSTTEST

\begin{tabular}{|c|c|c|c|}
\hline Coordination & Statistics & Pretest & Posttest \\
\hline \multirow{3}{*}{$\begin{array}{c}\text { High } \\
\text { (A1B1) }\end{array}$} & Total & 245,00 & 305,00 \\
\cline { 2 - 4 } & Mean & 49,0000 & 61,0000 \\
\cline { 2 - 4 } & SD & 1,22474 & 1,41421 \\
\hline \multirow{2}{*}{ Low } & Total & 232,00 & 319,00 \\
\cline { 2 - 4 } & Mean & 46,4000 & 63,8000 \\
\cline { 2 - 4 } & SD & 1,14018 & 1,30384 \\
\hline \multirow{2}{*}{$\begin{array}{l}\text { High } \\
\text { (A2B1) }\end{array}$} & Total & 244,00 & 338,00 \\
\cline { 2 - 4 } & Mean & 48,8000 & 67,6000 \\
\cline { 2 - 4 } & SD & .83666 & 1,14018 \\
\hline \multirow{2}{*}{$\begin{array}{l}\text { Low } \\
\text { (A2B2) }\end{array}$} & Total & 245,00 & 302,00 \\
\cline { 2 - 4 } & Mean & 49,0000 & 60,4000 \\
\cline { 2 - 4 } & SD & .70711 & .54772 \\
\hline
\end{tabular}

Data normality test used in this research is the Komogorov Smirnov method. The results of normality test of the data performed on each group of analysis is done with software program of SPSS version 20.0 for windows with a significance level of $5 \%$ or 0.05 . The data summary is presented in the table below:

TABLE II. NORMALITY TEST

\begin{tabular}{|l|c|l|}
\hline \multicolumn{1}{|c|}{ Data } & $\boldsymbol{p}$ & Note \\
\hline Pretest A1B1 & 0.759 & Normal \\
\hline Posttest A1B1 & 0.535 & Normal \\
\hline Pretest A2B1 & 0.953 & Normal \\
\hline Posttest A2B1 & 0.941 & Normal \\
\hline Pretest A1B2 & 0.941 & Normal \\
\hline Posttest A1B2 & 0.967 & Normal \\
\hline Pretest A2B2 & 0.759 & Normal \\
\hline Posttest A2B2 & 0.510 & Normal \\
\hline
\end{tabular}

Based on statistical analysis of normality test that has been done by using Kolmogorov Smirnov Z test, on all pretest and posttest data obtained from significance value of data normality test $\mathrm{p}>0.05$, which means data is normally distributed.

Homogenity test is done to test the equation of several samples whether they are homogeneous or not. The homogenity test was conducted to test the similarity in variance between pretest and posttest. Homogenity test used in this research is the Levene Test. Results of the test are shown in the table below:

TABLE III. HOMOGENITY TEST

\begin{tabular}{|l|c|c|}
\hline Group & Levene Statistic & Note \\
\hline Pretest & 0.362 & Homogeneous \\
\hline Posttest & 0.504 & Homogeneous \\
\hline
\end{tabular}

The statistical analysis of the homogenity test utilizing the Levene Test resulted in a significance value of $p \geq 0,05$ from the pretest-posttest. The result shows that the data group has a homogeneous variant. Therefore the population variant is homogeneous.

The research hypothesis test is conducted on the basis of data analyis results and an interpretation of ANAVA two-way analysis. The test results are shown in the table below:

TABLE IV. ANAVA TEST

\begin{tabular}{|l|c|c|c|}
\hline \multicolumn{1}{|c|}{ Source } & $\begin{array}{c}\text { Type III Sum of } \\
\text { Squares }\end{array}$ & $\boldsymbol{F}$ & Sig. \\
\hline Training Method & 12.800 & 9.660 & 0.007 \\
\hline Coordination & 24.200 & 18.264 & 0.001 \\
\hline $\begin{array}{l}\text { Training Method * } \\
\text { Coordination }\end{array}$ & 125,00 & 94.340 & 0.000 \\
\hline
\end{tabular}

Results from the ANAVA test shows a $\mathrm{p}$ significance value of $0.007<0.05$, and F stat of 9.660 , thus Ho is rejected. Therefore there are significant differences in the effects of fixed and changing target groundstroke shot training method on the groundstrokes precision of tennis athletes. Based on the analysis result, the changing target groundstroke training method resulted in an improvement in accuracy with an average posttest score of 64.0 compared to the posttest average score of 62.4 of the fixed target groundstroke shot training method. Therefore the research hypothesis which states that "there is a significant difference between the effects of the fixed target groundstroke shot training methods and changing target on the groundstroke precision of tennis athletes", has been proven.

From the ANAVA test result, it can be seen that the value of $\mathrm{p}$ significance amounts to $0.001<0.05$ and the F statistic amounts to 18.264 , therefore Ho is rejected. The result shows a significant difference in influence between good hand-eye coordination ability and poor hand eye coordination on the groundstroke accuracy of Tennis athlete. In conclusion, based on the analysis results, athletes with good hand eye coordination ability with an average posttest score of 64.3 have higher accuracy compared to athletes with poor hand eye coordination with an average posttest score of 62.1. This shows that the research hypothesis which states "there is a significant effect difference between high hand eye 
coordination capability and low hand eye coordination on the accuracy of groundstroke" has been proven.

From the ANAVA test result, it can be seen that the value of $\mathrm{p}$ significance amounts to $0.000<0.05$ and the F statistic amounts to 94.340 , therefore by this Ho is rejected. Based on that conclusion, the hypothesis which states "there is a significant interaction between groundstroke practice method (fixed and changing target) and hand-eye coordination (high and low) on the groundstroke accuracy of tennis players" has been proven.

The diagram for the interaction between groundstroke training method (fixed target and changing target) and handeye coordination (high and low) on the groundstroke precision of tennis athletes can be seen in Figure:

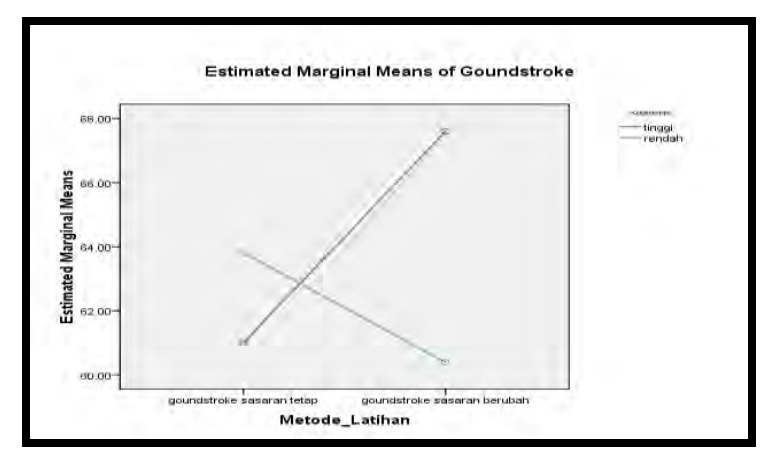

Fig. 1. Interaction between Practice Methods and Coordination

The results of paired variance analysis with Tukey's advanced test showed that there are 5 significantly different pairs, namely: (1) A1B1-A2B1, (2) A1B1-A1B2, (3) A2B1A1B2, (4) A2B1-A2B2, ( 5) A1B2-A2B2, with an additional pair with no difference: A1B1-A2B2.

\section{Discussion}

Differences in the effect of the fixed and changing target groundstroke training method and on the precision of tennis athletes' groundstroke

Based on the hypothesis testings it was found that there is a significant difference between the effects of fixed target groundstroke training method and variable targets on groundstroke precision of tennis athletes. The changing target groundstroke practice method has proven to gain more improvements towards the groundstroke accuracy than the fixed target method. The changing target practice is a striking process in which the player shoots the ball to different targets or switches from one target to another in one step, in other words a groundstroke with a changing target has various motion tasks where each strike on the target is different than the next (targets 1, 2, 3, and 4). "Varied practice: A practice schedule in which the same skill is rehearsed in a variety of different ways" [3].. It is a training where the same skill is trained using differrent methods. The effective groundstroke practice which improves groundstroke accuracy is the practice group with variable targets, moreso than the practice group with a fixed target. This is due to groundstroke practice with variable targets is more applicative in real-world gameplay. Through this practice method, athletes can learn to adapt to changing ingame conditions.

The advantages of practicing groundstroke with variable targets is that it sharpens precision and accuracy due to its variable and various targets. By doing so, the learner could shoot in different directions due to their familiarity with the practice method, which requires the learner to hit various targets. The method also lessens boredom during practice, which in turn allow players to develop the required instincts to perform grounstrokes to various directions.

Motor learning is a series of processes associated with practice and experience that lead to semi-permanent skill. Motor learning concerns with the processes underlying acquisition and motoric skills [3]. Taking into account the characteristics of target practice drills, said method also has advantages in terms of cognitive skills improvement. In this case, the drill is designed for athletes so that they are able to perform assigned tasks with specified targets. Athletes are expected to calculate their strikes and direct the ball with precision. Within the cognitive stage, learners focus on cognition oriented issues that associated with what should be done, and how to accomplish them. This stage is called as such due to the dominant concious mental state during the ealy stages of the learning process. In this stage almost all learners rely on declarative memory and information that are consciously manipulated and trained in formulating motor commands [3].

Seen through its effects on athletes, practice using variable targets method does have its advantages over using the fixed target method. The variable target drill method is more applicable ingame and can be applied to athletes who have good coordination. Fixed target drills are better applied to athletes with low coordination.

Motion in sports activities is the result of a stimulus that is processed in the brain and then responded through muscle contraction, after receiving orders from the nervous command system, i.e. the brain. Therefore motor skills are always associated with the internal motor system of the human body, in which the results can be observed in the movement of limb or other body parts. [4]. Learning motoric skills is series of exercise associations or experiences that could direct motoric movement towards performing certain motoric skills. Consequently, the change in motor skills in motor learning is an indication of motor learning process performed by an individual. Thus, the acquired motor skills are not only influenced by matured movements but also by motor learning process . Furthermore, a repeated motion will be saved in subject's memory which can come up anytime if there is a similar stimulus. Therefore, motion skills on sports has to be trained repeatedly so it will not easily lose from memory, so the person is skilled on every motion.

The skill improvement happened because there is an association of the knowledge obtained by the children on their previous meeting with the new knowledge so it will be more relevant if done repeatedly. It is based on the law of exercise theory by Thondrike, which states "the law of exercise shows that the main principle of learning is repetition; the more the material is repeated, the more it will be mastered" [7].

"From this perspective, most of the studies regarding schema theory have postulated that variable practice is more effective than constant practice in learning skills to be performed in unpredictable environments, or open skills". This means that most of research on schematic theory define that variations of training (changing) is more effective than repeated training (constant) on learning skills which are done on unexpected environment, or open skills [8]. 
The finding that children performed better in variable practice groups (practicing using four or five targets) as compared to constant practice groups (practicing using 1 or no specific target) supports the variability of practice”. This means that children in a variable training group (training by using four or five targets) is better than those in repeated training group (training using 1 or a specific target) [9].

The difference of effect on high hand-eye and low handeye coordination skills torwards the accuracy of groundstroke shots

Analysis result shows that there is a significant differences of influences between high hand-eye and low hand-eye coordination skills to the accuracy of groundstroke shots on Tennis athletes. Athletes with high hand-eye coordination skills are better than those with low hand-eye coordination skill to the accuracy of groundstroke shots. A person's coordination level determines its mastery on sport accuracy, moreover the accuracy belongs to the mastery of swing accuracy techniques on doing groundstroke shots. Group of players with high hand-eye coordination skills has a more accurate groundstroke shots than a group of players with low hand-eye coordination skills. Group of players with high hand-eye coordination skills has a higher potential than group with low hand-eye coordination skills. The influence of hand-eye coordination on groundstroke shot techniques is crucial to estimate the aim or target that needs to be achieved accurately, hand-eye coordination skills are important. In groundstroke shot techniques, a player will be found to having a good motion coordination if doing a swing technique correctly and neatly. Players who has good hand and eye coordination will result in a more accurate groundstroke shots, than players who cannot coordinate those two organs well. "Eye-hand coordination and proper head and body positioning are essential components of a good tennis stroke" [10].

Coordination is a skill that combines various nervous system of motion to an efficient motion pattern. The more complex the motion is, the bigger coordination level needed to perform with agility. Coordination has a close relation to other motor skills, such as balance, speed, and agility. Balance is interpreted as a skill in maintaining stance and body position on static balance while standing or while on dynamic balance [11].

Coordination is an ability of someone on integrating difference motions to a pattern of single motion effectively. Eye is a part of our sense to see around. Hand is a body part starting from the elbow to the fingertips or from the wrist to the fingertips [12]. Coordination is needed to almost every sports and games, and also important in a foreign situation or environment, such as game field, equipment, wheater, lighing, and opponent changes. Level of how good or bad someone's coordination is reflected on their ability to do a smooth, accurate, fast, and efficient motion. An athlete with good coordination will not only perform a skill flawlessly, but will be learning a new skill faster and easier. A good coordination can change and move faster from one motion pattern to another so to make an effective movement.

"A well-coordinated child will always acquire a skill quickly and be able to perform it smoothly. Compared with a child who might perform a movement with stiffness and difficulty, a well-coordinated young athlete will spend less energy for the same performance. Therefore, good coordination results in more skill effectiveness" [6].

The statement of Borpa above means that a child that can coordinate well will always get the skills faster and smoothly, than a child who performs the motion stiffly and with difficulty. A young athlete who coordinates well will be using little energy to a same performance. Therefore, a result of good coordination is more effective on a skill. Athlete with high coordination, on performing a groundstroke shot will be very different with athlete who is having a low coordination level. A child who can coordinate well will always obtain skills faster and smoother than a child who performs the motion stiffly and with difficulty. Likewise, a young athlete who coordinates well will use lesser energy for same performance, therefore, a result of good coordination is more effective on a skill. Players who has good hand and eye coordination will result in a more accurate shots, than players who cannot coordinate those two organs well. An athlete with good coordination will not only perform a skill flawlessly, but will be learning a new skill faster and easier. Good coordination means the ability to quickly change and move from one motion pattern to another, creating an effective movement [6]. Factors that affect motion learning are: (1) internal conditions; and (2) external conditions. Internal conditions include factors on every individual, or other attributes distinguishing one player to another. One of the internal condition factors is physical ability. Physical ability is related to eye-hand coordination which will affect a player performance either on movement trainings or matches. Thus, it can be concluded that a good eye-hand coordination is one of the requirements in the attempt to achieve maximum results for tennis players in delivering groundstroke shots [13].

The differences on skill mainly happened because of differences in physical quality. Other factor that need to be observed from a student's potential is a skill to recognize the position and movement that has been perfomed. Students who recognizes groundstroke position and movement that has been performed tend to correct their own movement which can also control them personally and it is important to be done in the fields or matches. High or low eye-hand coordination will affect the success in mastering a certain technique.

The interaction between training method (groundstroke shots with fixed target and changing target) and coordination (high or low) to the groundstroke shot accuracy

This research found that there is a significant interaction between groundstroke shot training method (fixed and changing target) and eye-hand coordination (high and low) to a Tennis athlete's groundstroke shot accuracy. The research result shows that groundstroke training method with changing targets is the most effective method for athlete with high eyehand coordination while groundstroke training method with fixed targets is more effective for athlete with low eye-hand coordination skill.

This is because the low coordination athlete can be assited more since constant target drill is not difficult as long as the target training is not changed so the athlete can perform drill easier, while for athlete with higher coordination is more suited to the changing drill method. This happens because changing target drill is more similar with real situation or 
condition on a match, so athlete with high coordination can perform it much easier than those with low coordination.

\section{CONCLUSIONS}

A conclusion is obtained based on the research results and data analysis as follows: (1) There is a significant difference between the effects of fixed target groundstroke training method and changing target groundstroke training method to a Tennis athlete's groundstroke accuracy. Groundstroke training method with changing targets are better than training with fixed targets for a Tennis athlete's groundstroke accuracy. (2) There are significant differences in the effects of high hand-eye and low hand-eye coordination skills to the accuracy of groundstroke shots in Tennis athletes. Athletes with high hand-eye coordination are better than those with low hand-eye coordination when it comes to accuracy of groundstroke shots. (3) There is a significant interaction between groundstroke shot training method (fixed and changing target) and eye-hand coordination (high and low) to a Tennis athlete's groundstroke shot accuracy.

\section{REFERENCES}

[1] Sukadiyanto. Teori dan metodologi melatih fisik petenis. Yogyakarta: FIK UNY, 2002

[2] A. Palmizal, Pengaruh metode latihan global terhadap akurasi ground stroke forehand dalam permainan tenis. Jurnal Media Ilmu Keolahragaan Indonesia, Volume 1. Edisi 2. (pp.112-117), 2011.
[3] W. H. Edward, Motor learning and control: from theory to practice. Sacramento: California State University, 2011.

[4] R. A. Schmidt, \& T. D. Lee, Motor learning and performance $\left(5^{\text {th }}\right.$ ed). Champaign: Human Kinetics, 2008.

[5] Sukadiyanto. Pengantar teori dan metodologi melatih fisik. Bandung: CV Lubuk Agung, 2011.

[6] O. T. Bompa, Theory and methodology of training. Toronto: Kendall/ Hunt Publishing Company, 1994.

[7] H. Rahyubi, Teori-teori belajar dan aplikasi pembelajaran motorik deskripsi dan tinjauan kritis. Bandung: Nusa Media, 2012.

[8] J. M. Francisco, M. Eva, \& Ordoño. Variability and practice load in motor learning. Revista internacional de ciencias del deporte (RICYDE), Vol. 39(11), pp. 62-78, 2015.

[9] S. J. Douvis, Variable practice in learning the forehand drive in tennis. Perceptual and Motor Skills, 101, 531-545, 2005.

[10] K. Mahadas, F. Mohammand, H. Samim, S. Jannapureddy, \& K. H Hung, "Timing differences in eye-hand coordination between experienced and inexperienced tennis players," Optometry \& Visual Performance. Volume 3 Issue 2, 2015

[11] M. Sajoto, Peningkatan dan pembinaan kekuatan kondisi fisik dan olahraga. Semarang: Dahara Prize, 1995.

[12] I. R. Mahendra, P. Nugroho, \& S. Junaidi, Kelentukan pergelangan tangan dan koordinasi mata tangan terhadap kemampuan melakukan pukulan forehand tenis meja. Journal of Sport Sciences and Fitness, Vol. 1 (1), 2012

[13] R. A. T. Wibowo, Perbedaan pengaruh model pembelajaran berganti dan pengulangan terhadap kemampuan pukulan groudstroke backhand tenis lapangan ditinjau dari koordinasi mata- tangan. Jurnal Ilmiah PENJAS, Vol 3. No.2, 2017. 